\title{
Quantifying the performance of a hybrid anion exchanger/adsorbent for phosphorus removal using mass spectrometry coupled with batch kinetic trials
}

\author{
Benjamin D. Martin, ${ }^{1[1]}$ Lueta De Kock, ${ }^{2}$ Maxime Gallot, ${ }^{3}$ Elodie Guery, ${ }^{4}$ \\ Sylvain Stanowski, ${ }^{5}$ Jitka MacAdam, ${ }^{1 *}$ Ewan J. McAdam, ${ }^{1}$ Simon A. \\ Parsons, ${ }^{1}$ and Bruce Jefferson ${ }^{1,2}$ \\ ${ }^{I}$ Cranfield Water Science Institute, Cranfield University, Bedfordshire, MK43 OAL, UK. \\ ${ }^{2}$ Department of Chemical Technology, Nanotechnology Innovation Centre (Water \\ Research Platform), University of Johannesburg, Doornfontein, South Africa, 2028
}

${ }^{3}$ Université Lille 1, Sciences et Technologies, Bâtiment A3 - Cité Scientifique, 59655

Villeneuve d'Ascq Cedex, France

4Génie Energétique et Environnement, National Applied Institute (INSA), Lyon, France

${ }^{5}$ Ecole Nationale Supérieure de Chimie de Montpellier, France

* Corresponding author. Tel: +44 1234 750111; fax: +44 1234751671.

E-mail address: j.macadam@Cranfield.ac.uk (J. MacAdam).

Word count: 4820

${ }^{[1]}$ Thames Water Utilities Ltd., Clearwater Court, Vastern Road, Reading, Berkshire RG1 8DB. Author ID (Scopus): 7402931917 
Quantifying the performance of a hybrid anion exchanger/adsorbent for phosphorus removal using mass spectrometry coupled with batch kinetic trials

Abstract: Increasingly stricter phosphorus discharge limits represent a significant challenge for the wastewater industry. Hybrid media comprising anionic exchange resins with dispersions of hydrated ferric oxide nanoparticles have been shown to selectively remove phosphorus from wastewaters, and display greater capacity and operational capability than both conventional treatment techniques and other ferric based adsorbent materials. Spectrographic analyses of the internal surfaces of a hybrid media during kinetic experiments show that the adsorption of phosphorus is very rapid, utilising $54 \%$ of the total capacity of the media within the first 15 minutes and $95 \%$ within the first 60 minutes. These analyses demonstrate the importance of intraparticle diffusion on the overall rate in relation to the penetration of phosphorus. Operational capacity is a function of the target effluent phosphorus concentration and for 0.1 mg.P.L ${ }^{-1}$, this is $0.29-0.51 \mathrm{mg} . P . g_{\text {media }}{ }^{-1}$, which is $8-13 \%$ of the exhaustive capacity. The adsorbed phosphorus can be selectively recovered, offering a potential route to recycle this important nutrient. The main implication of the work is that the ferric nanoparticle adsorbent can provide a highly effective means of achieving a final effluent phosphorus concentration of $0.1 \mathrm{mg} . P . \mathrm{L}^{-1}$, even when treating sewage effluent at $5 \mathrm{mg} . P \cdot \mathrm{L}^{-1}$.

Keywords: ferric nanoparticles; intraparticle diffusion; phosphorus recovery; regeneration; wastewater

\section{Introduction}

Current European discharge consents for phosphorus from sewage treatment vary between no standard for small works, to $1-2 \mathrm{mg} . P . \mathrm{L}^{-1}$ depending on the size of the 
plant and/or the ecological sensitivity of the discharge catchment. Adoption of either chemical precipitation [1] and/or enhanced biological reactions [2] enables resilient compliance to such standards. However, it is expected that future discharge consents will be based upon the background level of phosphorus in rivers, reported to be around $0.1 \mathrm{mg} . P . \mathrm{L}^{-1}[3]$, and in sensitive catchments, as low as $0.01 \mathrm{mg} . P . \mathrm{L}^{-1}$ [4]. Processes based on biological P removal are not capable of consistently achieving such tight discharge consents [5], and whilst possible with chemical precipitation, the dose requirements become economically unsustainable for effluent standards below 0.5 mg.P.L $\mathrm{L}^{-1}[6]$. Whichever treatment route is utilised, phosphorus is currently removed by converting the dissolved ion into a solid fraction as either inorganic precipitate (coagulation), microbial biomass (biological processes) or plant biomass (extensive systems). Notably, these approaches do not aid direct phosphorus recovery, although sludge fertilisation or struvite production from sludge liquors [7] enables reuse to a degree. Alternative approaches such as contact sorption processes are now being considered, since they can achieve low discharge levels, are mechanically robust, and are able to accommodate shock loads. In addition, some sorption materials offer the added benefit of direct recovery of phosphate as a by-product of the regeneration process. As well as protecting the environment, the use of these materials opens a direct route to nutrient recycling, which provides a revenue stream that can offset some of the capital cost of installing new adsorbent processes [8]. Whilst phosphorus recovery from dilute wastewater is not currently practiced, the potential is relatively large, with some reports suggesting that a substantial proportion of future phosphorus fertiliser demand could be met through recovery from wastewater $[9,10]$.

Recently, nanoparticle based adsorbent materials that use ion exchange beads as a support have been developed that provide both mechanical robustness and selectivity 
towards phosphorus [11-14]. Additionally, the materials can be reused for many service cycles using an alkaline regenerant, which deprotonates the hydrated ferric oxide particles, causing an electrostatic repulsion of phosphate back into solution [13]. The application of such systems is documented for arsenic removal from drinking water [15] and trace phosphorus removal [12].

The current paper builds on recent studies that have proven the effectiveness of iron nanoparticle based contact media in removing phosphorus in a variety of lab based $[11-13,16]$ and small pilot trials [17]. Overall, the majority of the studies have focussed on comparison of different media [13] and the impact of wastewater characteristics [17] with relatively little attention directed towards design issues such as the impact of loading rate and regeneration optimisation. Additionally, previous work has not separately quantified the individual components of such hybrid systems (i.e., their supporting anionic exchange resin, or their dispersion of iron nanoparticles) in terms of their ability to remove phosphorus. The current study addresses these knowledge gaps by focusing on the potential of the media to treat the entire phosphorus load entering a wastewater treatment plant, reducing a feed strength of $4.8 \mathrm{mg} . \mathrm{P} . \mathrm{L}^{-1}$ down to 0.1 mg.P.L ${ }^{-1}$ (98 \% removal), as well as separating out the phosphorus functional components of the hybrid resin and quantifying their individual contributions to performance. This differentiates from, and complements previous studies that have considered removal of trace concentrations at $0.26 \mathrm{mg} . P . \mathrm{L}^{-1}[12]$, synthetic or industrial wastewaters of 2 mg.P.L $L^{-1}$ and $3.8 \mathrm{mg} . P . L^{-1}$ [13], and real wastewaters at $2.2 \mathrm{mg.P.L} \mathrm{L}^{-1}$, (with a copper nanoparticle embedded resin) [11].

\section{Experimental}

Ferric nanoparticle adsorbent 
The adsorbent media, Layne ${ }^{\mathrm{RT}}$ (SolmeteX Co., Massachusetts), is a commercially available media, principally used for arsenic removal. The media comprises a strong base gel-type anion exchange resin with a quaternary ammonium functional group. Approximately $26 \%$ of the external and internal surfaces of the material are covered with iron in hydrated ferric oxide form. The base resin has a capacity of 1 meq. $\mathrm{mL}^{-1}$ (in the chloride form). The media was initially pre-conditioned by fluidisation in deionised water for 30 minutes to remove any remaining iron fines from the manufacturing process.

\section{Characterisation of media properties}

The media was size graded by dry sieving through a series of 10 " stainless steel sieves with mesh sizes ranging between $0.18 \mathrm{~mm}$ and $1.18 \mathrm{~mm}$. To fully characterise the performance of the media, it was first un-hybridised by passing $12 \mathrm{M} \mathrm{HCl}$ through a fixed bed of Layne ${ }^{\mathrm{RT}}$, which resulted in dissolution of the iron nanoparticles and their subsequent removal from the media. This left the base ion exchange resin, which was split into two sub samples and put into the chloride and sulphate form respectively using strong solutions of each as a regeneration step. The distribution of key elements within the media in its native and adapted forms (iron, chloride, sulphur, phosphorus) were measured using an FEI XL30 environmental scanning electron microscope (FEI UK Ltd, Cambridge, United Kingdom) in low-vac mode, and then subjected to elemental spectroscopic analysis using an Oxford Instruments EDX with INCA software (Oxford Instruments, Abingdon, Oxfordshire, United Kingdom). Prior to analysis, the beads were frozen in liquid nitrogen and cut into cross sections to enable imaging of the internal surfaces. Target points for spectroscopy were measured firstly at an area $15 \mu \mathrm{m}$ 
from the outer surface of the beads, and then across the diameter of each bead at intervals of $50 \mu \mathrm{m}$ (Figure 1).

\section{Kinetic studies and modelling}

Batch kinetic studies used $250 \mathrm{~mL}$ Erlenmeyer flasks into which 4 g. $\mathrm{L}^{-1}$ of media was placed, with $100 \mathrm{~mL}$ of either sewage effluent collected from a small trickling filter works containing $4.8 \mathrm{mg} . P . \mathrm{L}^{-1}$, and $205 \mathrm{mg} . \mathrm{SO}_{4}{ }^{2-}$, or synthetic wastewater (model solution) comprising $5 \mathrm{mg} . \mathrm{P} . \mathrm{L}^{-1}$ and $100 \mathrm{mg} . \mathrm{SO}_{4}{ }^{2-} \cdot \mathrm{L}^{-1}$ in deionised water. Each flask was stirred in an orbital shaker operated at $200 \mathrm{rpm}$, at $18{ }^{\circ} \mathrm{C}$ for one hour to obtain equilibrium. Kinetic data was obtained by taking sub samples every 10 minutes during a separate test. In all cases after sampling the media was separated from the solution immediately via vacuum filtration. Phosphorus and sulphate concentrations were determined using Spectroquant cell tests (Merck Millipore, UK). The methods are analogous to EPA 365 2+3, APHA 4500-P E, and DIN ISO 6878 for phosphorus, and EPA 375.4, APHA 4500-SO ${ }_{4}^{2-}$ E, and ASTN D516-11 for sulphate. Analysis of kinetic adsorption data was undertaken to compare fits to both intraparticle diffusion and film diffusion limited rate models $[18,19]$ :

$$
\begin{array}{ll}
\text { Intra-particle: } & q_{t}=k_{I P} t^{0.5} \\
\text { Film diffusion: } & \ln (1-F)=-k_{F D} t
\end{array}
$$

Where $q_{t}\left(\mathrm{mg} . \mathrm{P} . \mathrm{gmedia}^{-1}\right)$ is the solid phase concentration at time $t, \mathrm{~F}$ is the fractional attainment of equilibrium and $k$ is the rate constant defined in terms of a diffusion model $\left(k_{F D}\right)\left(\mathrm{min}^{-1}\right)$ or an intraparticle model $\left(k_{I P}\right)\left(\mathrm{mg} \cdot \mathrm{g}^{-1} \cdot \mathrm{min}^{-0.5}\right)$. Both models are plotted in linear form with the appropriateness of the respective models assessed through analysis of the linear regression constant [20]. 
Further analysis was conducted with respect to mass transfer where both the film diffusion coefficient, $k_{f}\left(\mathrm{~cm} \cdot \mathrm{s}^{-1}\right)$, and the intraparticle diffusion coefficient, $D\left(\mathrm{~cm}^{2} \cdot \mathrm{s}^{-1}\right)$, were calculated according to the following expressions $[18,21]$ :

$$
\begin{array}{ll}
\text { Intra-particle } & -\left[\log \left(1-\left\{\frac{Q_{t}}{Q_{e}}\right\}^{2}\right)\right]=\frac{4 \pi^{2} D t}{2.3 d^{2}} \\
\text { Film diffusion } & \ln \left(\frac{C_{t}}{C_{0}}\right)=-k_{f} \frac{A}{V} t
\end{array}
$$

Where $Q_{t}$ and $Q_{e}$ are the adsorbed amounts at time $t$ and at equilibrium (mg.P.g media $^{-1}$ ), $d$ is the media diameter $(\mathrm{cm}), C_{t}$ is the concentration at time $t, C_{0}$ is the initial concentration, $A$ is the area $\left(\mathrm{cm}^{2}\right)$ and $V$ is the solution volume (L). Combining the two coefficients enables calculation of the dimensionless Biot number $(B i)$ which indicates the ratio of the mass transfer resistance in the solid to the mass transfer resistance in the liquid:

$$
\text { Biot Number } \quad B i=\frac{k_{f} d}{D}
$$

\section{Column trials}

Fixed bed trials using $15 \mathrm{~mm}$ diameter, $200 \mathrm{~mm}$ long columns fed with final effluent from a small scale trickling filter works were used to generate saturation curves. Equal volumes of the adsorbent media $(10 \mathrm{~mL})$ were used in each case, with adjustments to empty bed contact time of $1,4,10$, and 20 minutes controlled with peristaltic pumps. Trials were run until 1000 bed volumes had passed through each column.

\section{Regeneration}

Regeneration was undertaken with $40 \mathrm{~mL}$ of media that had previously been saturated with phosphorus. Solutions containing $2 \% \mathrm{NaOH}$ or $5 \% \mathrm{NaCl}$ were passed through the 
columns using peristaltic pumps at an empty bed contact time of 4 minutes. Each bed volume of regenerant leaving the columns was analysed using Spectroquant Cell tests (Merck Millipore, UK) for phosphate (analogous to EPA 365 2+3, APHA 4500-P E, and DIN ISO 6878), nitrate (analogous to DIN 38405-9) and sulphate (analogous to EPA 375.4, APHA 4500-SO ${ }_{4}^{2-}$ E, and ASTN D516-11) concentrations.

\section{Results}

\section{Media properties}

The size of the carrier bead varied between 0.18 and $1.0 \mathrm{~mm}$ with a median size of 0.69 $\mathrm{mm}$ and a uniformity coefficient of 1.37 , consistent with commonly available ion exchange resins. The acid treated media with the iron removed was split into two samples, with half put into the chloride form and half put into the sulphate form. (Most ion exchangers are supplied in the chloride form, but Layne ${ }^{\mathrm{RT}}$ is supplied in the sulphate form.) This was done to quantify the performance of the media as an ion exchange resin in both forms, and later as a hybrid material with the addition of iron hydroxide nanoparticles. Spectrographic analysis of the chloride and sulphide form subsamples' surfaces revealed that $10.4 \%$ and $6.13 \%$ of the internal surfaces of the media was comprised of chlorine and sulphur by mass respectively, with a variance of distribution between the outer surfaces and core of the beads of less than $1.5 \%$ for each element. Expressing these amounts in terms of their charge characteristics is more useful for the present study and yields 369 eq $^{\underline{v}}$ of $\mathrm{Cl}$ and 393 eq $^{\underline{v}} \mathrm{~S}$. Whilst the mass of sulphur is lower on the base resin in comparison to chlorine, the overall charge imparted is very similar to the chloride, as a result of sulphate's higher ionic strength. Consequently, there is only a variance of $\sim 6 \%$ in terms of charge on the two subsamples. The inclusion of the iron nanoparticles into the ion exchange carrier increases the specific 
gravity of the bead to 1.6, which compares to typical levels for ion exchange media of $1.05-1.15$. Nanoparticle inclusion was found to be evenly spread throughout the beads with analysis of the distribution of iron as a percentage of the total surface mass indicating that the distribution of iron ranged from $24 \%$ at the bead edge to $28 \%$ at 220 $\mu \mathrm{m}$ from the edge, the approximate centre of the bead. This complements previous analysis that has indicated that the inclusion of nanoparticles within the ion exchange resins restricts the apparent pore diameter by $30 \%$ whilst increasing contact area by 7 $\%[13]$.

\section{Adsorption kinetics}

The chloride form subsample was exposed to a synthetic wastewater solution containing 5 mg.P.L. ${ }^{-1}$, and 33.4 mg.S.L ${ }^{-1}$ in batch kinetic experiments. Chlorine levels were measured at $15,65,115,165$ and $215 \mu \mathrm{m}$ from the surface and this analysis showed that a rapid displacement of chlorine from all depths of the carrier bead occurs as it is exposed to the typical ionic concentrations of wastewater. Between the outer surface and $15 \mu \mathrm{m}$ depth, chlorine dropped from $10.5 \%$ to $5.2 \%$ within the first ten minutes. Between 10 and 60 minutes however, the rate of loss proceeded more slowly, resulting in a final amount of $5 \%$ after 60 minutes. Similarly, a rapid decrease in chlorine mass was observed in the inner surfaces of the bead, with a drop of $10.5 \%$ to $6.2 \%$ within the first ten minutes, and a slower decrease to between $5.8 \%$ and $6.2 \%$ after 60 minutes (Figure 2). For increased clarity, only trend lines are plotted on Figures 2-5 and 7 , but in all cases these have $\mathrm{R}^{2}$ values $>0.98$.

Sulphur and phosphorus levels were also measured at the same locations within the beads. In the case of sulphur, rapid uptake over the first ten minutes saw levels rise 
from $0 \%$ to $1.8 \%$ in the outer surfaces, and $2.3 \%$ in the inner surfaces. There is a pronounced gap between the uptake efficiency of the outer and inner surfaces, with areas deeper than $65 \mu \mathrm{m}$ observed to hold an additional $0.2 \%$ to $1 \%$ sulphur by mass over the course of the experiment (Figure 3).

Phosphorus uptake onto the resin was much lower in comparison, rising from 0 to $0.09 \%$ of surface coverage after ten minutes for the outer surfaces, and between 0.09 $\%$ and $0.12 \%$ for the deeper surfaces. However, the rate of uptake is similar to that of sulphur, with final levels after 60 minutes only slightly higher than those after ten, at $0.11 \%$ and around $0.13 \%$ for the outer and inner surfaces respectively (Figure 4 ). As with conventional ion exchange systems, sulphate out-competes phosphate, since sulphate is present at much higher concentrations in typical municipal wastewaters. It is therefore the sulphate that displaces the majority of the chloride, in comparison to that displaced by phosphate.

The base media of the Layne ${ }^{\mathrm{RT}}$ hybrid ion exchanger is sold in the sulphate form as a result of its patented production process. Removing the iron nanoparticles and putting the base resin back into the sulphate form allows the separation of the hybrid components, and an assessment to be made about each in terms of phosphorus removal. Phosphorus uptake from the base resin in sulphate form is minimal - achieving at best $0.04 \%$ coverage of the internal surfaces after one hour of exposure to the synthetic solution (Figure 5). In terms of capacity, this form of the media is only able to achieve $0.4 \mathrm{mg} . P . \mathrm{gmedia}^{-1}$ at these environmentally relevant conditions.

Using the media in its complete form, with the ion exchange component in the sulphate form, and around $25 \%$ of the internal surfaces made up of iron results in a significant improvement in the phosphorus removal performance. Kinetic experiments with real wastewater $\left(4.8 \mathrm{mg} . \mathrm{P} . \mathrm{L}^{-1}, 204 \mathrm{mg} . \mathrm{SO}_{4}{ }^{2-} . \mathrm{L}^{-1}\right)$ and a synthetic solution (5 
mg.P.L $\left.\mathrm{L}^{-1}, 100 \mathrm{mg} . \mathrm{SO}_{4}{ }^{2-} \cdot \mathrm{L}^{-1}\right)$ revealed that the adsorption of phosphorus using the Layne $^{\mathrm{RT}}$ media was very rapid such that $54 \%$ of the total capacity was utilised within the first 15 minutes and $95 \%$ within the first 60 minutes (Figure 6).

No significant difference was observed in P removal between the real and synthetic solutions (using an ANOVA $F$-test, which returned a $p$ value $<0.05$ ), indicating that other competing ions or solid components in wastewater do not influence the overall uptake rate of phosphorus. In comparison, a previous study reported that 67 $\%$ of the capacity was reached within the first 10 minutes using iron oxide tailings [22], faster than in the current case, probably due to the smaller particle diameter of $68.6 \mu \mathrm{m}$ for the tailings in comparison to the present study's $0.69 \mathrm{~mm}$ bead diameter. Analysis of the kinetic data, in both studies, fit to a three stage model whereby mass transfer initially occurs across the boundary layer surrounding a particle, followed by surface adsorption and then diffusion into the internal structure of the material [23]. Further analysis with respect to rate controlling mechanisms suggests that intraparticle diffusion controls only marginally over film diffusion as the rate limiting step (Equations 1 and 2), with $\mathrm{R}^{2}$ fit values of 0.98 and 0.84 respectively. This contrasts with commonly used adsorbents such as activated carbon where intraparticle diffusion is reported to dominate as the rate controlling mechanism [24].

Kinetic analysis at different positions within the bead demonstrates the importance of intraparticle diffusion on the overall rate in relation to the penetration of phosphorus. Critically, phosphorus coverage within the inner sections of the bead was observed to lag behind those at the surface indicating the switch over of mechanism (Figure 7). 
To illustrate, phosphorus coverage increased from $0.14 \%$ after 10 minutes to $0.26 \%$ after 60 minutes in a layer extending from the surface to $115 \mu \mathrm{m}$ into the bead. In contrast, at $165 \mu \mathrm{m}$ and $215 \mu \mathrm{m}$ from the bead edge, phosphorus coverage was only $0.07 \%$ and $0.05 \%$ at 10 minutes respectively, only reaching levels consistent with positions closer to the surface after 48 minutes. At this point in time, $90 \%$ of the total adsorption had been completed. Fitting the data to intraparticle and film diffusion models confirms these observations, based on the criteria of linearity and the need for the line to pass through the origin. A distinct switch in appropriateness of fit was observed such that the outer two layers fit the film diffusion model best and the inner two layers fit the intraparticle diffusion model better (Equations 1 and 2). The $115 \mu \mathrm{m}$ layer was intermediate between the two and indicates the zone at which intraparticle diffusion starts to become the dominant mechanism. Further analysis with respect to mass transfer revealed the intraparticle diffusion coefficient $D$ (Equation 3 ) to decrease from $2.6 \times 10^{-6} \mathrm{~cm}^{2} . \mathrm{s}^{-1}$ to $1.4 \times 10^{-6} \mathrm{~cm}^{2} . \mathrm{s}^{-1}$ as the phosphorus concentration decreased from 105 mg.P.L $L^{-1}$ to 5 mg.P.L $L^{-1}$ (Figure 8). Whilst these relatively high concentrations of phosphate would not normally be seen in a wastewater plant, they were used here to fully characterise the system. The influence of concentration on $D$ reflects the impact of surface diffusion due to the heterogeneity of the media surface [24]. The corresponding film diffusion coefficient, $k_{f}$, was calculated as $2.8 \times 10^{-3} \mathrm{~cm} \cdot \mathrm{s}^{-1}$ (Equation 4), which indicates that the media operates with a Biot number of 175 (Equation 5). The mechanistic implication of this is that the media operates in the intermediate zone where both film and intraparticle diffusion are important, but with an emphasis on the latter [25].

\section{Column experiments}


Using real wastewater and the complete form of the Layne ${ }^{\mathrm{RT}}$ media, alteration of the empty bed contact time (EBCT) between 1 and 20 minutes caused a significant change in the shape of the breakthrough curve, with the mass transfer zone being more sharply defined as the EBCT increased (Figure 9).

To illustrate, at an EBCT of 1 minute, immediate leakage of phosphorus is observed with an effluent quality of $0.1 \mathrm{mg} . P . \mathrm{L}^{-1}$ exceeded within the first $10 \mathrm{bed}$ volumes. Overall, at an EBCT of 1 minute, the concentration of phosphorus in the effluent increased approximately linearly from $0.39 \mathrm{mg} . P . \mathrm{L}^{-1}$ at 100 bed volumes to 4.17 mg.P.L $\mathrm{L}^{-1}$ at 900 bed volumes. In contrast, at an EBCT of 20 minutes, no breakthrough was observed for the first 280 bed volumes, with the total capacity reached after 600 bed volumes (Figure 10).

\section{Regeneration}

Regeneration of hybrid adsorbent/ion exchange media typically involves combinations of $\mathrm{NaCl}$ and $\mathrm{NaOH}$ at concentrations between $2 \%$ and $5 \%$ passed through a fixed bed of the media for 10 bed volumes [12]. Comparison of the efficacy of each component revealed that the majority of desorption occurs within the initial bed volumes such that $65 \%$ and $88 \%$ of the total $\mathrm{P}$ desorbed by each solution was eluted by the end of the first bed volume for the $5 \% \mathrm{NaCl}$ and $2 \% \mathrm{NaOH}$ solutions respectively (Figure 11).

Further desorption ceased within two bed volumes with the $\mathrm{NaCl}$ solution but continued with the $\mathrm{NaOH}$ solution such that no elution of phosphate was recorded after 5 bed volumes. 3457 mg.P.L. ${ }^{-1}$ was desorbed using $\mathrm{NaOH}$, and $251 \mathrm{mg} . P . \mathrm{L}^{-1}$ using $\mathrm{NaCl}$. The phosphate desorbed with the $\mathrm{NaCl}$ regeneration is consistent with the level expected to be taken up by the media via ion exchange, of around $10 \%$ of the total [8]. The $\mathrm{NaCl}$ acts mainly on the ion exchange resin, disrupting the electrostatic interaction 
holding the phosphate ion as an outer sphere complex [13]. In contrast, the phosphate bound to the ferric nanoparticles is held in an inner sphere complex, the reversal of which requires the ferric to be deprotonated, generating a negatively charged surface that repels the bound phosphate. As a consequence, regeneration with $\mathrm{NaOH}$ only acts on the nanoparticles, leaving the ionic material bound to the resin in place. Whilst this reduces capacity by around $10 \%$ on reusing the media (as some phosphate will also remain on the ion exchange sites), it does have the advantage of generating a purer phosphate stream for downstream recovery, since very few of the competing ions will be present in the solution. To illustrate, during desorption with the $\mathrm{NaOH}$ solution, the average concentration of eluted material over five bed volumes was $691 \mathrm{mg} . P . \mathrm{L}^{-1}, 39$ mg. $\mathrm{NO}_{3}{ }^{-} \cdot \mathrm{L}^{-1}$ and $55 \mathrm{mg} \cdot \mathrm{SO}_{4}{ }^{2-} \cdot \mathrm{L}^{-1}$. In contrast, over the same 5 bed volumes, desorption with $\mathrm{NaCl}$ produced a solution containing $50 \mathrm{mg} . \mathrm{P} . \mathrm{L}^{-1}, 1008 \mathrm{mg} \cdot \mathrm{NO}_{3}{ }^{-} \cdot \mathrm{L}^{-1}$ and 721 $\mathrm{mg} . \mathrm{SO}_{4}{ }^{2-} \cdot \mathrm{L}^{-1}$. A similar contamination issue has been reported elsewhere during the regeneration of activated alumina where the recovered solution contained 2200 mg.P.L${ }^{1}, 400 \mathrm{mg} . \mathrm{SO}_{4}{ }^{2-} \cdot \mathrm{L}^{-1}$, and $1600 \mathrm{mg} \cdot \mathrm{Al} \cdot \mathrm{L}^{-1}[21]$.

\section{Discussion}

The key observation from this study is that the ferric component within the hybrid anion exchange material works as a highly selective phosphorus adsorbent, responsible for removing $90 \%$ of the total phosphorus attributed to the media as a whole. The role of the base ion exchange material is mostly as a supporting structure for the immobilisation and stabilisation of the ferric nanoparticles, and actually exhibits little functional benefit to the removal of phosphorus. This means that the media can be considered a mono component system in the main, since the only ion to be removed from wastewater by adsorption onto the ferric nanoparticles is phosphate. An additional 
benefit of this is that the phosphorus can also be selectively recovered from the media during regeneration of the ferric adsorbent sites. In terms of rate kinetics, the media's uptake of phosphate is only marginally limited by intraparticle diffusion in comparison to film diffusion. This shows that whilst unbound nanoparticles of ferric are theoretically able to adsorb more phosphorus, and at a faster rate than a bulk material, immobilising them in a bead such as the current media has little impact on uptake performance. This is likely to be a consequence of the high internal surface area of the supporting ion exchange bead material, with internal pore surfaces coated, but not clogged with nanoparticles.

Similarity between the kinetic behaviour established in the current study (with the media exhibiting a Biot number of 175), and other work is found with respect to arsenate and phosphate adsorption onto granular ferric hydroxide with Biot numbers of 182 and 102 respectively [26]. However, comparison with activated carbon reveals smaller Biot numbers (indicating that film diffusion is more important) for metals [27] and pesticides [28] with much larger Biot numbers (indicating that intraparticle diffusion is more important) for reactive dye uptake [18]. The differences are partially related to the molecular weight of the adsorbates as both $k_{f}$ and $D$ decrease as molecular weight increases [29]. However, comparison across the studies shows the major difference is in terms of the intraparticle diffusion coefficient $D$ with the current study returning a value of $1.4 \times 10^{-6} \mathrm{~cm}^{2} . \mathrm{s}^{-1}$ for an environmentally relevant concentration of phosphorus at $5 \mathrm{mg} . \mathrm{L}^{-1}$, and reported values of $0.13-0.61 \times 10^{-10} \mathrm{~cm}^{2} . \mathrm{s}^{-1}$ for dye adsorption onto activated carbon [20], $0.6 \times 10^{-10} \mathrm{~cm}^{2} . \mathrm{s}^{-1} \times 10^{-10} \mathrm{~cm}^{2} \cdot \mathrm{s}^{-1}$ for pesticide adsorption on activated carbon [28], and $1.2 \times 10^{-6} \mathrm{~cm}^{2} \cdot \mathrm{s}^{-1}$ for phosphate uptake onto alumina [21], indicating the relative ease of $\mathrm{P}$ uptake into the internal structure of the 
present media compared to other systems, as a result of the enhanced affinity imparted by the ferric nanoparticle component.

Considering the treatable volume before breakthrough for different final effluent discharge consents and $\mathrm{EBCT}$, the greatest variation was observed at either low or high effluent breakthrough limits (Figure 10). For instance, to achieve an effluent concentration of $0.1 \mathrm{mg} . \mathrm{P} . \mathrm{L}^{-1}$, an EBCT of 20 minutes can treat 275 bed volumes, whilst an EBCT of one minute treats less than 10 bed volumes. The difference in treatable volumes between contact times of one minute and 20 minutes reduced from 160 bed volumes at $1 \mathrm{mg} . P . \mathrm{L}^{-1}$, to 50 bed volumes at $2 \mathrm{mg} . P . \mathrm{L}^{-1}$, suggesting that the operational hydraulic rate can be optimised for different final effluent levels. Converted to capacity, the performance ranged between $0.29 \mathrm{mg} . P . \mathrm{gmedia}^{-1}$ and $0.51 \mathrm{mg} . \mathrm{P} . \mathrm{g}_{\mathrm{media}}{ }^{-1}$ to meet a $0.1 \mathrm{mg} . P . \mathrm{L}^{-1}$ final effluent standard as the EBCT increased from 1 to 20 minutes. Assessment of the operational suitability of these runtimes can be considered with reference to other contact processes typically encountered in water and wastewater treatment such as ion exchange and activated carbon media. In the case of the former, typical operating cycles of several hundred bed volumes are common as the media is regenerated on site [30], whereas adsorption processes typically run for thousands of bed volumes between regeneration cycles. However, this reflects the fact that the regeneration of activated carbon has to be completed off site (because it requires reactivation using heat), and that dilute components are being adsorbed. Previous trials with the ferric nanoparticle resin in treating feed solutions of $0.63 \mathrm{mg} . P . L^{-1}[7]$, and 0.26 mg.P.L. ${ }^{-1}[11]$ reported exhaustive bed life of 4000 and 16000 bed volumes respectively. Consequently, the operating cycle of the ferric nanoparticle adsorbent reflects the load being treated but in all cases is similar to existing systems, which should enhance the ease of implementation. The operational capacity is also a function of the permitted 
effluent phosphorus concentration with compliance to $0.1 \mathrm{mg} . \mathrm{P} . \mathrm{L}^{-1}$, reducing the operating capacity to $0.29-0.51 \mathrm{mg} . P$. gmedia $^{-1}$ which is only $8-13 \%$ of the exhaustive capacity.

The application of this technology can range from polishing a treated stream to treatment of the full phosphorus load in a typical wastewater. However, previous economic assessments indicate that it is currently more expensive than traditional approaches when treating the full load [8]. Because of this, its likely application in the near future would be as a polishing process downstream of chemical and/or biological $\mathrm{P}$ removal stages, where extended bed life and reduced regeneration cost can be expected. According to the current work, it is possible to further reduce the economic impact of the regeneration process [8] by reducing the associated chemical cost by using a maximum of four bed volumes of $\mathrm{NaOH}$ to regenerate the media at the end of each operational cycle.

\section{Conclusion}

The iron nanoparticle embedded resin offers a suitable means of phosphorus removal to provide a final effluent quality of $0.1 \mathrm{mg} . P . \mathrm{L}^{-1}$. The operating cycle time could vary between 200 and upwards of 1000 bed volumes between regeneration cycles, depending on operational configuration (i.e. fixed beds of media in parallel vs. in series). The flexible implementation offered by this technology caters for the complexity associated with phosphorus removal and has the potential to treat the full phosphorus load in a typical wastewater or to polish a treated stream. However to treat a full load is currently not economically viable and more likely application in the near future would be as a polishing stage downstream of the main P removal process. The present study has 
shown that there is a limiting EBCT below which mass transfer is negatively impacted through limitations associated with intraparticle diffusion. As such a recommended EBCT of 10 - 20 minutes is suggested, equivalent to a mid to high range for traditional adsorption processes. The economics of the whole process are heavily influenced by the regeneration process due to the chemical costs involved but the current work indicates that significant chemical cost savings during the regeneration are possible.

\section{Acknowledgements}

The authors would like to thank the UK Water Industry Research organisation, and the industrial sponsors of the work: Anglian Water, Northern Ireland Water, Northumbrian Water, Severn Trent Water, Wessex Water, and Yorkshire Water for their financial and technical support throughout the project. In addition the authors would to thank Dr Paul Sylvester, of SolmeteX Co., for supply of the media sample.

\section{References}

1. Yang K, Li Z, Zhang H, Qian J and Chen G. Municipal wastewater phosphorus removal by coagulation. Environ Technol. 2010;31:601-609.

2. Morse GK, Brett SW, Guy JA, Lester JN. Review: Phosphorus removal and recovery technologies. SciTotal Environ. 1998;212:69-81.

3. EA 2000. EA Aquatic eutrophication of England and Wales: a management strategy Environment Agency Bristol 2000.

4. Hansen B. Engineering news: Environmental engineering: Long-term plan seeks to reduce phosphorus in Spokane River. Civil Eng. 2006;76:24-25. 
5. Kuba T, Smolders GJF, van Loosdrecht MCM, Heijnen JJ. Biological phosphorus removal from wastewater by anaerobic-anoxic sequencing batch reactor. Water Sci Technol. 1993;27(5-6):241-2.

6. Clauson-Kaas J, Sander Poulsen T, Neergaard-Jacobsen B, Guildal T, Thirsing C. Economic and environmental optimization of phosphorus removal. Water Scie Techn. 2004;50(7):243-248.

7. Saidou H, Ben Moussa S, Ben Amor M. Influence of airflow rate and substrate nature on heterogeneous struvite precipitation. Environ Technol. 1009;30:75-83.

8. Martin BD, Parsons SA, Jefferson B. Removal and recovery of phosphate from municipal wastewaters using a polymeric anion exchanger bound with hydrated ferric oxide nanoparticles. Water Sci Technol 2009;60:2637-2645.

9. Cordell D, Neset T-SS. Phosphorus vulnerability: A qualitative framework for assessing the vulnerability of national and regional food systems to the multi dimensional stressors of phosphorus scarcity. Global Environ Chang. 2014;24:108-122. 10. Reijnders L. Phosphorus resources, their depletion and conservation, a review. Resour Conserv Recy 2014;93:32-49.

11. Zhao D, SenGupta AK. Ultimate removal of phosphate using a new class of anion exchanger. Water Res. 1998;32:1613-1625.

12. Blaney LM, Cinar S, SenGupta AK. Hybrid anion exchanger for trace phosphate removal from water and wastewater. Water Res. 2007;41:1603-1613.

13. Pan B, Wu J, Pan B, Lv L, Zhang W, Xiao L, Wang X, Tao X, Zheng S.

Development of polymer-based nanosized hydrated ferric oxides (HFOs) for enhanced phosphate removal from waste effluents. Water Res. 2009;43:4421-4429

14. Sengupta S, Pandit A. Selective removal of phosphorus from wastewater combined with its recovery as a solid-phase fertilizer. Water Res. 2011;45(11):3318-3330. 
15. Zhang Q, Pan B, Zhang W, Pan B, Zhang Q, Ren H. Arsenate removal from aqueous media by nanosized Hydrated Ferric Oxide (HFO)-loaded polymeric sorbents: Effect of HFO loadings. IndEng Chem Res 2008;47:3957-3962.

16. Nur T, Johir MAH, Loganathan P, Nguyen T, Vigneswaran S, Kandasamy J. Phosphate removal from water using an iron oxide impregnated strong base anion exchange resin. J Ind Eng Chem. 2014;20(4):1301-1307.

17. Midorikawa I, Aoki H, Omori A, Shimizu T, Kawaguchi Y, Kassai K, Murakami T. Recovery of high purity phosphorus from municipal wastewater secondary effluent by a high-speed adsorbent. Water Sci Technol. 2008;58:1601-1607.

18. Khraisheh MAM, Al-Degs YS, Allen SJ, Ahmad MN. Elucidation of controlling steps of reactive dye adsorption on activated carbon. Ind Eng Chem Res. 2002;41:16511657.

19. Boyd GE, Adamson AM, Myers LS. The exchange adsorption of ions from aqueous solutions by organic zeolites II Kinetics. JAm Chem Soc. 1949;69:2836-2842.

20. Choy KKH, Porter JF, McKay G. Intraparticle diffusion in single and multicomponent acid dye adsorption from wastewater onto carbon. Chem Eng J 2004;103:133-145.

21. Urano K, Tachikawa H. Process development for removal and recovery of phosphorus from wastewater by a new adsorbent. 2. Adsorption rates and breakthrough curves. IndEng Chem Res.1991;30:1897-1899.

22. Zeng L, Li X, Liu J. Adsorptive removal of phosphate from aqueous solutions using iron oxide tailings. Water Res. 2004;38:1318-1326.

23. Cheung WH, Szeto YS, McKay G. Intraparticle diffusion processes during acid dye adsorption onto chitosan. Bioresource Technol. 2007;98:2899-2904.

24. Cooney DO, Adsorption design for wastewater treatment CRC Press Florida (1998). 
25. Sonetaka N, Fan H, Kobayashi S, Chang H, Furuya E. Simultaneous determination of intraparticle diffusivity and liquid film mass transfer coefficient from a singlecomponent adsorption uptake curve. J Haz Mat 2009;164:1447-1451.

26. Sperlich A, Werner A, Genz A, Amy G, Worch E, Jekel M. Breakthrough behavior of granular ferric hydroxide (GFH) fixed-bed adsorption filters: Modeling and experimental approaches. Water Res. 2005;39:1190-1198.

27. Quek SY, Al-Duri B. Application of film-pore diffusion model for the adsorption of metal ions on coir in a fixed-bed column. Chem Eng Process: Process Intensif. 2007;46:477-485.

28. Baup S, Jaffre C, Wolbert D, Laplanche A Adsorption of pesticides onto granular activated carbon: Determination of surface diffusivities using simple batch experiments. Adsorption 2000;6:219-228.

29. Walker GM, Weatherley LR. Fixed bed adsorption of acid dyes onto activated carbon. Environ Pollut. 1998;99:133-136.

30. McAdam EJ, Pawlett M, Judd SJ. Fate and impact of organics in an immersed membrane bioreactor applied to brine denitrification and ion exchange regeneration. Water Res. 2010;44:69-76. 
Figure 1: ESEM image of a cross section of a single bead, showing targets for spectrographic analysis

Figure 2: Displacement of chlorine from base resin in chloride form during kinetic trial in synthetic solution containing $5 \mathrm{mg} . \mathrm{P} . \mathrm{L}^{-1}$, and $100 \mathrm{mg} \cdot \mathrm{SO}_{4}{ }^{2-} \cdot \mathrm{L}^{-1}$

Figure 3: Uptake of sulphur by base resin in chloride form during kinetic trial in competition with phosphate in solution

Figure 4: Uptake of phosphorus from base resin in chloride form during kinetic trial, in competition with sulphate in solution

Figure 5: Uptake of phosphorus from base resin in sulphate form during kinetic trial, in competition with sulphate in solution

Figure 6: Kinetic curves of phosphorus removal using Layne ${ }^{\mathrm{RT}}$ hybrid media against real wastewater and a model wastewater solution

Figure 7: Kinetic progression of phosphorus coverage within the Layne ${ }^{\mathrm{RT}}$ hybrid media Figure 8: The relationship between concentration and the diffusion rate of phosphorus within the bead structure

Figure 9: Saturation curves for varying empty bed contact times

Figure 10: Comparison of breakthrough performance with varying contact times Figure 11: Use of $5 \% \mathrm{NaCl}$ vs. $2 \% \mathrm{NaOH} \mathrm{P}$ desorption profiles 